\title{
Europa tussen samenwerking en opportunisme : de internationale fusiepraktijk als voorbeeld voor Europese integratie
}

\author{
Citation for published version (APA):
}

Kool, C. J. M., \& Olie, R. L. (1997). Europa tussen samenwerking en opportunisme : de internationale fusiepraktijk als voorbeeld voor Europese integratie. NIBOR, Netherlands Institute of Business Organization and Strategy Research. NIBOR Research Memorandum No. 10 https://doi.org/10.26481/umanib.1997010

Document status and date:

Published: 01/01/1997

DOI:

10.26481/umanib.1997010

Document Version:

Publisher's PDF, also known as Version of record

\section{Please check the document version of this publication:}

- A submitted manuscript is the version of the article upon submission and before peer-review. There can be important differences between the submitted version and the official published version of record. People interested in the research are advised to contact the author for the final version of the publication, or visit the DOI to the publisher's website.

- The final author version and the galley proof are versions of the publication after peer review.

- The final published version features the final layout of the paper including the volume, issue and page numbers.

Link to publication

\footnotetext{
General rights rights.

- You may freely distribute the URL identifying the publication in the public portal. please follow below link for the End User Agreement:

www.umlib.nl/taverne-license

Take down policy

If you believe that this document breaches copyright please contact us at:

repository@maastrichtuniversity.nl

providing details and we will investigate your claim.
}

Copyright and moral rights for the publications made accessible in the public portal are retained by the authors and/or other copyright owners and it is a condition of accessing publications that users recognise and abide by the legal requirements associated with these

- Users may download and print one copy of any publication from the public portal for the purpose of private study or research.

- You may not further distribute the material or use it for any profit-making activity or commercial gain

If the publication is distributed under the terms of Article $25 \mathrm{fa}$ of the Dutch Copyright Act, indicated by the "Taverne" license above, 
Europa tussen samenwerking en opportunisme: De internationale fusiepraktijk als voorbeeld voor Europese integratie

C. Kool \& R. Olie

NIBOR/RM/97/10

http://www.unimaas.nl/ document/fdewb.htm

J.E.Lit. code:

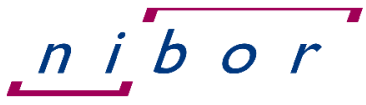

Netherlands Institute of

Business Organization

and Strategy Research

University of Maastricht

Faculty of Economics and Business Administration

P.O. Box 616

6200 MD Maastricht

The Netherlands

Phone: ++3143 - 3883794 


\title{
Fax : $++3143-3258495$ \\ Europa tussen samenwerking en opportunisme
}

\author{
de internationale fusiepraktijk als voorbeeld voor Europese integratie \\ Clemens Kool en René Olie \\ Universiteit Maastricht
}

\section{Inleiding}

De onrust en twijfel over de EMU neemt overal in Europa in snel tempo toe. In veel landen is de groep Eurosceptici groeiende. Eind vorig jaar stelde de socioloog De Swaan dat de discussie in Nederland over de Europese integratie nog in een pre-politiek stadium verkeert. ${ }^{1}$ Inmiddels is de discussie zelfs in Nederland in volle hevigheid losgebarsten. ${ }^{2}$ Bovendien blijkt de meerderheid van de Nederlandse bevolking geen vertrouwen meer te hebben in de euro. ${ }^{3}$

Kenmerkend voor het debat over de EMU is dat het zich concentreert op de economische voor- en nadelen van de EMU. De consensus daarbij lijkt te zijn dat de netto-baten van de EMU beperkt en onzeker zijn. ${ }^{4}$ Economische argumenten kunnen dus niet de doorslag geven. Dit suggereert dat de EMU vooral een politiek doel dient, zoals recent ook ruiterlijk werd toegegeven door de oud-voorzitter van de Europese Commissie, Jacques Delors. Het belang van de EMU is volgens Delors dat "de ervaring van gedeelde souvereiniteit op monetair gebied tot een belangrijke stap voorwaarts in de richting van echte politieke integratie zal leiden". 5

Deze politieke doelstelling lijkt ver weg en het wezenlijke debat over Europese politieke integratie staat nog in de kinderschoenen. Het Verdrag van Maastricht kent weliswaar naast

${ }^{1}$ Zie NRC Handelsblad, 28 december 1996.

${ }^{2}$ Exemplarisch is de stellingname tegen de huidige route naar de EMU door circa zeventig hoogleraren economie in de Volkskrant van 13 februari 1997 met het daaropvolgende publieke debat.

${ }^{3}$ NRC Handelsblad 26 februari 1997.

${ }^{4}$ Zie bijvoorbeeld C.J.M. Kool, De Andere Kant van de Ene Munt, 1996, Universiteit Maastricht voor een afweging van kosten en baten.

${ }^{5}$ Zie J. Delors, The Economic and Monetary Union in the Framework of a United Europe, 1996, SUERF-lezing, Maastricht. 
bepalingen over de EMU ook twee politieke paragrafen met betrekking tot de interne en externe veiligheid. Maar de huidige intergouvernementele conferentie (igc), die zich hier over buigt, boekt weinig tot geen voortgang. Terwijl deze in juni 1997 in Amsterdam toch moet resulteren in een nieuw Europees verdrag waarin met name de Europese organisatie en besluitvorming beter geregeld is. De bestaande meningsverschillen zijn echter fundamenteel en lijken nauwelijks overbrugbaar. Terwijl bijvoorbeeld Duitsland gecharmeerd is van een echte politieke unie (federale structuur), is Frankrijk de voorvechter van intergouvernementele besluitvorming. Meer dan een uitgekleed en minimaal verdrag is in Amsterdam niet haalbaar. Verdergaande politieke integratie op basis van vrijwilligheid bljft daarom voorlopig een utopie. Blijft over het forceren van politieke integratie via een monetaire unie met alle risico's van dien.

De kans op succes is moeilijk in te schatten. Immers, de EMU is een uniek experiment in grensoverschrijdende samenwerking tussen landen is zonder historische precedenten. Men dient daarom te zoeken naar analogieën. Wij constateren dat het proces van Europese integratie veel weg heeft van een fusieproces tussen bedrijven. Hierbij kunnen de Europese landen worden voorgesteld als zelfstandige ondernemingen die zich aaneensluiten om samen sterker te staan, waarbij ze hun zelfstandigheid voor een (groot) deel overdragen aan een 'hoger lichaam', een centrale besturingseenheid. In deze bijdrage hanteren we grensoverschrijdende fusies van ondernemingen als metafoor voor de Europese integratie, in casu de EMU. Bekende factoren achter het succes of falen van fusies worden toegepast op de casus van de Europese integratie.

\section{Ervaringen met grensoverschrijdende fusies}

In een groot aantal bedrijftakken is de (internationale) vervlechting van bedrijven de laatste decennia sterk toegenomen. Vaak ligt hieraan de motivatie ten grondslag dat samenwerken moet om de internationale concurrentie aan te kunnen. Vervlechting is er in soorten en maten. Voorbeelden zijn verschillende typen van strategische allianties - waaronder joint ventures-, fusies en acquisities. Deze samenwerkingsvormen variëren in de mate waarin partners samenwerken (niveau van vervlechting), de mate waarin sprake is van gelijkwaardigheid tussen de partijen, en de duurzaamheid. Fusies en joint ventures veronderstellen meestal beide min of meer gelijkwaardigheid tussen de partners. Anderzijds zijn fusies en acquisities vormen van volledige samenwerking, terwijl het bij joint ventures en andere strategische allianties slechts om gedeeltelijke samenwerking gaat. Bij acquisities verliest één van de partijen de 
zelfstandigheid, bij een fusie gaan beide op in een nieuwe eenheid. Bij een strategische alliantie (joint venture) behouden de betrokken partners in principe hun souvereiniteit, hoewel ze op deelgebieden met elkaar samenwerken. Bovendien hebben joint ventures een eindige looptijd. Het samenwerkingsverband houdt op te bestaan wanneer de doelen zijn bereikt, dit in tegenstelling tot fusies en acquisities die een permanent karakter hebben.

Samenwerkingsverbanden mislukken vaak. In de literatuur worden slagingspercentages van 50 procent genoemd, zowel voor joint ventures als voor fusies en acquisities. ${ }^{6}$ Internationale samenwerking is in dit opzicht waarschijnlijk nog moeilijker dan samenwerking tussen bedrijven binnen eenzelfde land. Bekende voorbeelden van mislukte grensoverschrijdende fusies zijn, Hoogovens-Hoesch (1972-1982), Fokker-VFW (1969-1980), Dunlop-Pirelli (1971-1981), en pogingen daartoe zoals AMRO Bank-Generale Bank (1988), KLM-British Airways (1992), en Renault-Volvo (1993). Hiertegenover staat natuurlijk ook een groot aantal gelukte fusies, maar het slagingspercentage zal niet veel boven de $50 \%$ uitkomen. Bovendien kennen zelfs succesvolle fusies vaak een zeer moeizame start.

Succes of mislukking is zelden aan één factor toe te schrijven, maar is meestal een combinatie van externe en interne factoren. Olie (1996) onderscheidt in dit verband zes belangrijke determinanten van het succes van internationale fusies. ${ }^{7}$

In onderstaande analyse beschouwen we de huidige Europese integratie als een fusieproces. Immers, de partners worden min of meer als gelijkwaardig beschouwd en de doelstellingen hebben een permanent karakter. Het is in principe ook mogelijk de EMU als een strategische alliantie te beschouwen, gezien het feit dat op dit moment slechts een beperkte overdracht van souvereiniteit voorzien wordt. Naar onze mening moet een echte fusie het einddoel zijn, gezien de politieke ambities, en is de joint venture slechts een tussenstation. Voor de analyse is het onderscheid tussen fusie en joint venture betrekkelijk, omdat de succesfactoren achter fusies in het algemeen ook gelden voor acquisities en lossere samenwerkingsverbanden.

\footnotetext{
${ }^{6}$ Zie R.L. Olie, European Transnational Mergers, 1996, Universiteit Maastricht.

${ }^{7}$ Zie R.L. Olie (Ibid.)
} 


\section{Determinanten fusiesucces}

\subsection{Externe omstandigheden}

Kenmerkend voor veel samenwerkingsvormen is het duale karakter, de mengeling van gemeenschappelijk en eigenbelang. Als gevolg zijn veel samenwerkingsvormen inherent instabiel. Dit is evident bij losse samenwerkingsverbanden zoals joint ventures, maar deze spanning is ook aanwezig bij fusies. Op basis van eigenbelang wordt tot innige samenwerking met de andere partij besloten, maar tegelijkertijd blijft men zich na de fusie lange tijd identificeren met de belangen van de oorspronkelijke organisatie. Juist vanwege de aanwezigheid van eigenbelang is het gevaar van opportunisme in de beginperiode aanwezig. Daarom zijn gunstige externe omstandigheden vooral in het begin uitermate belangrijk. Naarmate het samenwerkingsverband langer bestaat en er meer vertrouwen tussen de partners is opgebouwd, neemt het gevaar van opportunisme af.

Negatieve externe schokken, zoals een economische recessie, vergroten zeker in het begin de spanning tussen beide partners. Dit kan negatieve invloed hebben op de motivatie en verwachtingen van de partijen, maar kunnen ook de strategische voordelen van de fusie wijzigen. Het bestaan van interdependenties, oftwel de wederzijdse voordelen die men aan de samenwerking ontleent, is één van de manieren om het najagen van eigenbelang te beperken. Juist door sterke wijzigingen in de situatie kan het wederzijdse belang teniet worden gedaan en opportunisme in de hand werken, zeker wanneer alternatieven beschikbaar zijn.

Net als bedrijven kunnen ook landen getroffen worden door negatieve schokken, zoals een wereldwijde recessie of een oliecrisis. Aan de schokken zelf valt niets te doen, maar normaliter bezitten nationale economieën automatische stabilisatoren - in de vorm van monetair en budgettair beleid - die de gevolgen van zo'n schok dempen. Bij de EMU is er bewust voor gekozen die schokdempers uit te schakelen om misbruik door politici te voorkomen. Daarmee is het kind met het badwater weggegooid. Mocht het dus macroeconomisch tegenzitten in de beginfase van de EMU, dan is het - qua aanpassing aan de schok - elk voor zich. Vanzelfsprekend zal opportunisme toenemen. Zelfs het uiteen vallen van de EMU behoort in zo'n situatie tot de mogelijkheden. Immers, de kosten om uit de EMU te stappen zijn zeker in het begin beperkt, en het alternatief - een eigen munt - reëel. 


\subsection{Strategische aanpassing en besluitvorming}

Een tweede factor is strategische fit. Strategische fit, oftewel de synergie die ontstaat bij samenvoeging van twee ondernemingen, is één van de belangrijkste voorwaarden voor fusiesucces. Onvoldoende strategische fit heeft vaak te maken met de kwaliteit van het besluitvormingsproces. Besluitvormers maken beoordelingsfouten als gevolg van onvolledige informatie, de tijdsdruk waaronder ze het besluit moeten nemen, hun neiging om vast te houden aan een eenmaal gemaakte keuze, of hun behoefte de deal snel af te ronden. ${ }^{8}$ Dit kan leiden tot een onjuiste inschatting van de acquisitie- of fusievoordelen, maar ook tot een onvoldoende voorbereiding op de implementatiefase.

De relevantie van dit punt voor de Europese integratie behoeft nauwelijks toelichting. Het lijkt erop dat door de interne markt het overgrote deel van de potentiële synergieën op economisch vlak al is gerealiseerd. Monetaire en politieke integratie voegen daar weinig aan toe en dienen hooguit ter versteviging van die interne markt. Over de daaruit voortvloeiende bijwerkingen is nauwelijks nagedacht. Het besluitvormingsproces rond bijvoorbeeld het Verdrag van Maastricht vertoont alle hierboven beschreven kenmerken. Tijdsdruk en de behoefte het momentum vast te houden zijn belangrijker geweest dan het objectief afwegen van de alternatieven. Ook de overgangsfase van waarschijnlijk tien jaar (1992-2002) wordt vooral gekenmerkt door onverwachte problemen en crises.

Een tweede oorzaak voor een gebrekkige fit zijn, zoals hierboven beschreven, sterke veranderingen in de marktstructuur. Olie (1996) beschrijft hoe bekende grensoverschrijdende fusies in de jaren zeventig zoals Hoogovens-Hoesch (samen Estel) en Fokker-VFW kort na hun samengaan te maken kregen met de effecten van de eerste oliecrisis: economische krimp in plaats van groei. Onder deze omstandigheden verdwenen de voordelen van de fusie al snel. Voor landen geldt in feite hetzelfde. Elke ontwikkeling die leidt tot een belangrijke verschuiving van economische of politieke machts- en concurrentieverhoudingen binnen Europa, impliceert een verandering in de kosten-baten analyse van elk land. In de perceptie van één land, kunnen de voordelen van de EMU zo snel verdwijnen.

Hoewel strategische fit een noodzakelijke voorwaarde is voor succes, is het geen voldoende voorwaarde. In de implementatiefase moeten de beoogde voordelen van de fusie daadwerkelijk

\footnotetext{
${ }^{8}$ Zie R.L. Olie (Ibid.)
} 
worden gerealiseerd. Dan blijkt de praktijk vaak weerbarstiger dan de theorie. Conflicten en wedijver, wij-zij tegenstellingen, weerstand tegen verandering, misverstanden en communicatieproblemen, karakteriseren vaak de post-fusiefase bij gefuseerde organisaties. In feite is het fusie-integratieproces pas beëindigd wanneer de oorspronkelijke delen van de nieuwe organisatie op een coherente manier werken aan het bereiken van de nieuwe doelstellingen, en wanneer de leden van de organisatie zich identificeren ('thuis voelen') met de nieuwe organisatie. Organisatie-identiteiten en oude loyaliteiten blijken echter vaak nog jarenlang gehandhaafd te worden. Deze fase is vaak moeizaam en duurt langer dan is voorzien. Hoe lang en hoe moeizaam is sterk afhankelijk van de volgende factoren.

\subsection{Cultuurverschillen}

Cultuurverschillen, zowel organisatie- als landgebonden verschillen, spelen een belangrijke rol. Internationale fusies, acquisities of joint ventures komen onder andere relatief moeilijk van de grond door fundamentele verschillen in waarden en opvattingen die van land tot land verschillen. ${ }^{9}$ Meer dan bij een fusie van twee organisaties met dezelfde nationaliteit kan dit betekenen dat een gemeenschappelijk referentiekader ontbreekt. Daarnaast verschillen landen ook in wetgeving, de rol van de overheid en van financiële instituties, het opleidingsysteem en arbeidsverhoudingen. Algemeen kan men stellen dat hoe groter de culturele verschillen zijn, des te groter het conflictpotentieel. Hierbij spelen drie additionele factoren een rol. Ten eerste, de mate van integratie. Hoe sterker de beoogde integratie, des te groter het risico dat het succes van de nieuwe organisatie wordt verstoord door verschillen in (nationale) cultuur en managementstijl. Bij beperkte integratie worden beide organisaties hooguit aan de top met elkaar verbonden en is er nauwelijks sprake van (wederzijdse) aanpassing of contact tussen de beide organisatie-eenheden.

Een tweede factor is de mate waarin groepen hun 'identiteit' willen behouden. Hoe aantrekkelijker de nieuwe 'identiteit', des te soepeler zal het integratieproces verlopen. Een laatste factor is de aard van de relatie tussen de partner-organisaties. Bij een gelijkwaardige relatie tussen de partners, zoals bij een fusie, dienen de partners tot een consensus te komen ten aanzien van de strategische richting van de nieuwe onderneming en haar interne

\footnotetext{
${ }^{9}$ Zie G.H. Hofstede, Culture's Consequences, International Differences in Work-related Values, Sage, Beverly Hills, 1980.
} 
functioneren. Belangrijke cultuurverschillen vergroten dan de kans dat managers van beide organisaties verschillende opvattingen hebben over het nemen van risico's, besluitvormingsprocedures, leiderschapstijl, enzovoort. Dit zal het ontwikkelen van een gemeenschappelijk beleid en de integratie van beide groepen bemoeilijken of zelfs verhinderen. Bij een ongelijkwaardige relatie (acquisitie) speelt dit minder. De overgenomen onderneming heeft zich dan te schikken naar de overnemende partij. ${ }^{10}$

Op het gebied van nationale cultuur, gewoontes, normen en waarden en instituties, bestaan er binnen de Europese Unie enorme verschillen. ${ }^{11}$ Dientengevolge is het conflict-potentieel in ruime mate aanwezig. Voorlopig wordt dit met name beperkt door het principe van subsidiariteit. Wet- en regelgeving en uitvoering ervan vindt plaats op het laagst mogelijke niveau. In feite komt dit neer op een bewuste beperking van de integratie. Op korte termijn neemt dit spanningen weg, op lange termijn echter vertraagt het het fusieproces en vermindert het de kansen op succes. Bovendien is zelfs in dit stadium al duidelijk dat Europese besluitvorming een toenemende invloed op het functioneren van nationale economieën heeft.

Daarnaast is het de Europese politieke top nog steeds niet gelukt een voor de gemiddelde burger begrijpelijke en aantrekkelijke nieuwe Europese 'identiteit' neer te zetten. Voor de meerderheid is Europa een abstract en nietszeggend begrip. Het is daarom niet verwonderlijk dat individuen zich eerder meer dan minder vastklampen aan hun oude nationale identiteit.

Tenslotte leidt de gelijkwaardigheid van de deelnemende landen aan het onderhandelingsproces regelmatig tot langdurige pat-stellingen. De huidige besluitvormingsstructuur van de Europese Unie heeft hiervoor geen oplossing. Op belangrijke beleidsterreinen is een gekwalificeerde meerderheid nodig en kunnen individuele landen bovendien een veto uitspreken. Hoewel niet goed denkbaar is hoe autonome landen gedwongen kunnen worden tot hen onwelgevallige besluiten, is de huidige procedure op zijn

${ }^{10}$ Een goed voorbeeld op landen-niveau is in dit verband de Duitse eenwording van 1989 die meer als overname dan als fusie moet worden gezien.

${ }^{11}$ Een illustratief voorbeeld is de moeite die men heeft om een Europese NV tot stand te brengen. Het plan voor een Europese NV, de zogenaamde Societas Europea, die het mogelijk maakt dat ondernemingen juridisch over de grenzen heen kunnen fuseren, stamt al uit de jaren zestig. Keer op keer blijkt het voorgesteld ontwerp stuk te lopen op de nationale verschillen in ondernemingstoezicht en werknemersparticipatie. Hoewel er met behulp van de verschillende EU-richtlijnen wel enige uniformiteit tot stand is gebracht in de nationale regelgeving ten aanzien van ondernemingen, zijn de echte moeilijke punten tot op heden blijven liggen. 
minst een rem en wellicht een splijtzwam voor het integratieproces. De igc zou hierin verandering moeten brengen, maar zoals gezegd is de kans op succes klein.

\subsection{Identiteit}

'Sociale identiteit' is een tweede - aan cultuur verwante - bron van conflict in samenwerkingsverbanden. Het gaat hier vooral om de vraag waar iemand zich thuis voelt. Mensen maken deel uit van verschillende groepen of categorieën, identificeren zich hiermee en worden door anderen hiermee geïdentificeerd. Ze zijn Nederlander of Duitser, Limburger of Hollander, NS-er of KLM-er. Die groep-identificatie bepaalt in sterke mate iemands loyaliteit. Sociaal-psychologisch onderzoek laat zien dat dit categorisatieproces waarbij mensen zichzelf en anderen categoriseren als behorend bij dezelfde subgroep ('the ingroup') of hier niet tot behorend ('the outgroup') gevolgen heeft voor de samenwerking. ${ }^{12}$ Mensen uit de 'outgroup' worden in het algemeen negatiever beoordeeld en vijandiger behandeld dan mensen van de 'ingroup'. Met andere woorden, conflicten komen in dit geval niet voor uit verschillen in normen en waarden tussen groepen of collectiviteiten, maar uit het feit dat er groepen of collectiviteiten bestaan, en het onderscheid 'wij' en 'zij' gemaakt kan worden. Dit fenomeen ziet men overal terug, zowel in organisaties ('wij van marketing en zij van productie'), als op nationaal niveau ('wij en de Duitsers').

De neiging om onderscheid te maken tussen wij en zij is over het algemeen sterker naarmate mensen zich meer verbonden voelen met de organisatie waarvan ze deel uitmaken. De mate waarin de loyaliteit zich richt op de eigen groep en 'ingroup'-bias optreedt zal daarnaast afhangen van de mate waarin beide groepen zich door symbolen, locatie, doelstellingen, enzovoort in de nieuwe organisatie van elkaar onderscheiden. Het denken in afzonderlijke groepen in plaats van een gemeenschappelijke groep verhindert in sterke mate een goede samenwerking.

Zoals hierboven al duidelijk is geworden is er nauwelijks sprake van een Europese identiteit. In Europa voelt de Nederlander zich Nederlander, beschouwt de Fransman zich Fransman en identificeert elk zich met de eigen nationale belangen, Wat goed is voor Nederland of Frankrijk staat voorop, niet wat goed is voor Europa. Kortom, de Europese natie

\footnotetext{
${ }^{12}$ Zie onder ander H. Tajfel \& J.C. Turner, The social identity theory of intergroup behavior. In S. Worchel \& W.G. Austin (Eds), Psychology of Intergroup Relations, Cambridge University Press, Cambridge, 1985.
} 
bestaat (nog) niet, evenmin als de Europese staatsburger. ${ }^{13}$

Nationale identiteiten spelen een belangrijke rol, zelfs of misschien juist tussen (buur-) landen met sterk verwante culturen. Nederland en Duitsland zijn wat dat betreft een goed voorbeeld. Terwijl deze twee landen in de Europese politieke arena vaak gelijk optrekken vanuit een gezamenlijk referentiekader, leeft er aan de basis een sterk 'wij-zij' gevoel dat overwonnen moet worden voor tot goede samenwerking kan worden gekomen. Meer algemeen hechten landen - en hun bevolking - aan hun taal en cultuur en nationale symbolen als vlag, taal, munt of voetbalelftal. Het feit dat de nationale munten dreigen te verdwijnen, impliceert daarom geenszins dat daarmee ook het gevoel van 'eigenheid' verdwijnt. Landen die als entiteit al honderden jaren bestaan, zullen zichzelf niet zomaar opheffen om op te gaan in een groter geheel.

\subsection{Organisatievorm na de fusie}

De organisatiestructuur van een samenwerkingsverband omvat de verdeling van taken en bevoegdheden en de manier waarop coördinatie tussen de samenstellende delen tot stand wordt gebracht. De bestuurlijke structuur bepaalt niet alleen in welke mate cultuur- en identiteitsproblemen een rol spelen, maar ook in hoeverre andere conflictbronnen zoals de verdeling van schaarse middelen, de mate van interdependentie en de mate van doelovereenstemming tussen de nationale groepen in de nieuwe organisatie een rol gaan spelen.

Zoals hierboven aangegeven beperkt een los samenwerkingsverband, waarbij de constituerende delen bijvoorbeeld hooguit financieel van elkaar afhankelijk zijn, de kansen op spanningen die voortkomen uit culturele verschillen en identiteitsconflicten. Een los samenwerkingsverband werkt wellicht goed onder gunstige omstandigheden, maar wordt problematisch wanneer de omstandigheden minder gunstig worden, vooral wanneer de ene partij beter presteert dan de andere. In een dergelijke situatie van schaarste ontstaat er al snel dysfunctioneel conflict tussen de partijen over de schuldvraag. Een tweede bezwaar is dat de kans op een zelfstandige koers van één van beide partijen toeneemt aangezien het uiteenvallen van het verband met minder hoge kosten gepaard gaat dan bij sterke integratie.

\footnotetext{
${ }^{13}$ Zie C. Goodhart, The political Economy of Monetary Union, in P. Kenen (ed.), Understanding Interdependence: the Macroeconomics of the Open Economy, 1995, ch.8.
} 
Hoewel sterke integratie wellicht de kans op opportunisme vermindert, kent het ook een aantal bezwaren. In principe is de kans op conflict veel groter, zeker wanneer er sprake is van grote nationale verschillen en men vast wil houden aan een eigen identiteit. Om de kansen op conflict te reduceren en cohesie te vergroten is het belangrijk om integratiemechanismen tot stand te brengen. Voorbeelden zijn het ontwikkelen van doelen en identificatiesymbolen, het uitwisselen van sleutelfiguren en het instellen van selectie- en socialisatieprocedures en beloningssystemen, die de gemeenschappelijkheid en de wederzijdse afhankelijkheid tussen de groepen tot uitdrukking brengen. Vaak zijn dit soort integratiemechanismen moeilijk tot stand te brengen. Ten eerste spelen practische problemen een rol, maar stuiten ze ook op weerstand. Zo zijn 'grensoverschrijdende symbolen' niet gemakkelijk te introduceren omdat bestaande symbolen een belangrijk onderdeel van de eigen identiteit vormen.

Bij fusies speelt nog een bijkomend probleem. De principiële gelijkwaardigheid van beide partners stelt belangrijke eisen aan de manier waarop de nieuwe organisatie gestalte krijgt. Beide partners zullen verlangen dat er een evenredige verdeling van invloed in de organisatie zichtbaar wordt, bij voorbeeld via de samenstelling van de leiding, de naamgeving, de plaats van het hoofdkantoor en het investeringsbeleid. Hoewel begrijpelijk, werkt dit de benodigde integratie vaak tegen omdat het eerder de verdeeldheid dan de eenheid benadrukt.

Dit tweede aspect is ook in het Europese integratieproces dominant. Elk land houdt precies in de gaten of aan het principe van evenredige vertegenwoordiging voldaan wordt. Dit geldt zowel voor de personele invulling van Europese topposities als voor bijvoorbeeld de locatie van nieuw op te richten Europese instellingen. Identificatiesymbolen voor een geïntegreerd Europa ontbreken evenals procedures om de beste man op de beste plaats te krijgen. In plaats van de onderlinge afhankelijkheid wordt vooral de eigen overblijvende autonomie benadrukt. ${ }^{14}$ In dit opzicht zou de euro als symbolische eerste aanzet voor de Europese eenheid kunnen fungeren. Tegelijkertijd geeft de beslissing om op de nieuwe eurobiljetten ruimte open te laten voor nationale symbolen hoezeer de nationale identiteit nog van betekenis blijft.

\footnotetext{
${ }^{14}$ Op landenniveau lijkt vooral België met zijn eeuwige strijd tussen Vlaamse en Waalse belangen model te hebben gestaan voor de Europese Unie.
} 


\subsection{Leiderschap}

Leiderschap wordt veelal als een kritische factor gezien voor het slagen van veranderingsprocessen. Het leiderschap moet de eenheid symboliseren en als voorbeeld dienen voor de overige organisatieleden. Vooral in fusies waar een dominant referentiekader ontbreekt, is de effectiviteit van het leiderschap sterk afhankelijk van de samenwerking en goodwill die tussen de partners bestaat. Nog belangrijker is het dat het top-management een gezamelijke visie heeft op de toekomst van de gefuseerde onderneming. Een dergelijke gedeelde visie versterkt de onderlinge cohesie en maakt het topmanagement voor de lagere echelons geloofwaardiger. In dit opzicht vormt het management één van de belangrijkste integratiemechanismen in een gefuseerde onderneming. Natuurlijk is het hebben van een gezamenlijke visie op zich onvoldoende. Het collectief leiderschap moet in staat zijn deze visie over te dragen aan de basis. Vooral in de beginfase kan zwak en verdeeld leiderschap fragmentatie in de hand werken.

Ook hier scoort Europa laag. Met name de halfjaarlijkse bijeenkomsten van Europese regeringsleiders - het meest zichtbare symbool van Europese samenwerking - dragen bij aan het beeld van een Europa waarin elk land zoveel mogelijk op het behalen van korte-termijn eigenbelang uit is. Wisselingen van de wacht - denk aan Chirac voor Mitterand - kunnen een forse koerswijziging betekenen; van een gedeelde visie is geen sprake, en alle enquêtes wijzen uit dat het met het overdragen van die visie op de bevolking slecht gesteld is.

\section{Hoe kansrijk is de EMU?}

Het proces van Europese integratie waarvan de EMU een belangrijk onderdeel is, heeft veel weg van een strategische alliantie die geleidelijk moet uitmonden in een volledige fusie. Hierbij kunnen de Europese landen worden voorgesteld als zelfstandige ondernemingen die zich aaneensluiten om samen sterker te staan, waarbij ze hun zelfstandigheid voor een toenemend deel overdragen aan een 'hoger lichaam', een centrale besturingseenheid. De Europese eenwording is nog niet zo ver voortgeschreden om al te spreken van een echte fusie. Daartoe ontbreekt een echt centraal coördinatiemechanisme, zoals dat in het Duitse model van een federale unie wordt voorgesteld. In dat geval zou men de Europese regering als de raad van bestuur kunnen opvatten en de landen als geografische business units of divisies.

Overigens moet opgemerkt worden dat het bij de meeste joint ventures en fusies slechts om twee partners gaat; in dit geval zijn het er vijftien. De complexiteit van de besluitvorming 
en de kans op belangenconflicten nemen sterk toe. Cultuurverschillen en coördinatie- en communicatieproblemen leiden bovendien tot extra spanningen. Kortom, de kans op succes neemt af.

Het is duidelijk dat Europese integratie een ambitieus project is. Het is misschien zelfs verwonderlijk dat we zo ver gekomen zijn. Het blijft echter moeilijk de kans op uiteindelijk succes in te schatten. Economische argumenten lijken daarbij niet doorslaggevend te zijn. Het politieke debat mist handen en voeten. In dit artikel hebben wij geprobeerd aan te geven aan welke organisatorische randwoorden het Europese integratieproces zou moeten voldoen om het een redelijke kans op verder succes te geven. Hiervoor is een instrumentarium gebruikt dat eerder met is toegepast op grensoverschrijdende samenwerking tussen bedrijven.

We hebben hierbij duidelijk gemaakt dat fusies onderhevig zijn aan centrifugale en centripetale krachten. Voorbeelden van centrifugale krachten zijn wisselend economisch succes, slechte fit, grote cultuurverschillen en sterke subgroepidentificatie, een gebrekkige organisatievorm en een zwak topmanagement. Om als eenheid te opereren hebben organisaties behoefte aan integratiemechanismen die voor voldoende centripetale tegenkrachten zorgen, zodat de afzonderlijke delen een coherent geheel (gaan) vormen. Een voorbeeld is de euro. Deze kan op zichzelf gezien worden als symbolisch en feitelijk integratiemechanisme dat een Europese identiteit dichterbij brengt. Van de euro mogen echter geen wonderen worden verwacht. Als de overige noodzakelijke randvoorwaarden ontbreken, is de EMU en de introductie van de euro onvoldoende. Onze analyse vanuit de fusiepraktijk laat zien dat het kader waarbinnen nu EMU en euro van start gaan, nog vele gevaren herbergt. Het resultaat van die analyse staat samengevat in tabel 1 .

De eerste kolom bevat de zes sleutel-factoren, die in kolom 2 nader gepreciseerd worden. Per argument is in de derde kolom aangegeven in welke mate het ons inziens bijdraagt aan het succes van de EMU. De uitkomst is niet erg hoopgevend, maar geeft aan in welke richting aan verdergaande Europese integratie moet worden gewerkt. Het huidige tijdpad zou daarbij geen bindende restrictie moeten zijn. 
Tabel 1 Haalt de EMU het jaar 2000?

\begin{tabular}{|c|c|c|}
\hline Factoren: & Succes bij: & $\begin{array}{l}\text { Invloed op } \\
\text { succes EMU: }\end{array}$ \\
\hline 1. omgevingsfactoren: & $\begin{array}{l}\text { - hoge economische groei } \\
\text { - weinig alternatieven }\end{array}$ & $\begin{array}{l}? \\
-\end{array}$ \\
\hline $\begin{array}{l}\text { 2. strategische aansluiting } \\
\text { en besluitvorming: }\end{array}$ & $\begin{array}{l}\text { - duurzame fit } \\
\text { - aandacht voor strategisch doel en integratie } \\
\text { - kwaliteit besluitvorming }\end{array}$ & $\begin{array}{l}? \\
- \\
-\end{array}$ \\
\hline 3. culturele verschillen: & $\begin{array}{l}\text { - gelijksoortige normen, waarden en instituties } \\
\text { - beperking culturele conflicten } \\
\text { - zwakke identiteit } \\
\text { - geen principiële gelijkwaardigheid partners }\end{array}$ & $\begin{array}{l}- \\
+ \\
- \\
-\end{array}$ \\
\hline 4. organisatie-identiteit: & $\begin{array}{l}\text { - zwakke wij/zij tendensen } \\
\text { - zwakke onderlinge concurrentie }\end{array}$ & - \\
\hline 5. organisatievorm na fusie: & - snelle en sterke integratie & - \\
\hline 6. top-management: & $\begin{array}{l}\text { - gezamenlijke visie } \\
\text { - overdracht visie aan alle betrokkenen }\end{array}$ & - \\
\hline
\end{tabular}

